\title{
Effect of $\mathrm{BaO}-\mathrm{Al}_{2} \mathrm{O}_{3}-\mathrm{B}_{2} \mathrm{O}_{3}-\mathrm{SiO}_{2}$ glass additive on densification and dielectric properties of $\mathrm{Ba}_{0.3} \mathrm{Sr}_{0.7} \mathrm{TiO}_{3}$ ceramics
}

\author{
Z. H. WU, H. X. LIU, M. H. CAO, Z. Y. SHEN, Z. H. YAO, H. HAO and D. B. LUO \\ State Key Lab of Advanced Technology for Materials Synthesis and Processing, Wuhan University of Technology, \\ Wuhan 430070, P.R. China
}

\begin{abstract}
To fabricate the energy storage ceramics with large sizes for pulsed power transmission line, the densification behavior and dielectric properties of $\mathrm{Ba}_{0.3} \mathrm{Sr}_{0.7} \mathrm{TiO}_{3}$ with 0-8 mass $\% \mathrm{BaO}-\mathrm{Al}_{2} \mathrm{O}_{3}-\mathrm{B}_{2} \mathrm{O}_{3}-\mathrm{SiO}_{2}$ glass additive were investigated. With increasing glass content, both the densification temperature and densification rate decreased remarkably. The shrinkage rate mismatch caused by green density gradient also reduced remarkably, which contributed to the fabrication of large sizes of ceramic with dense microstructure. The additions of glass phase decrease the dielectric constant. However, the breakdown strength of the samples can be increased by a factor of 1.5 over the pure BST because of the modification of the microstructure. For the samples containing 4 mass $\%$ glass additions, optimal dielectric properties were obtained: dielectric constant is 440, dielectric loss is $3.5 \times 10^{-3}$ at $1 \mathrm{MHz}$, and breakdown strength is $16.4 \mathrm{kV} / \mathrm{mm}$.
\end{abstract}

Key-words: Barium strontium titanate, Densific ation behavior, Breakdown strength, Glass additive

[Received October 29, 2007; Accepted December 11, 2007] @2008 The Ceramic Society of Japan

1. Introduction

Dielectrics with high dielectric constant are being developed for use in compact pulsed power system in order to achieve high specific energy densities and physical size reduction. ${ }^{1)}$ Currently, energy storage dielectrics that are being used in transmission line are deionized water $\left(\varepsilon_{\mathrm{r}}=80\right)$ and polymer $\left(\varepsilon_{\mathrm{r}}=2-10\right)$. Their replacement by the solid dielectric such as a ceramic is highly desirable. Typical candidate ceramics that are being studied in this regard are $\mathrm{TiO}_{2},{ }^{2), 3)} \mathrm{SrTiO}_{3}{ }^{4), 5)}$ and $\mathrm{BaTiO}_{3}{ }^{6}$ ) Because the tradeoff between high dielectric constant and high breakdown strength has been identified as a major issue in the search for suitable dielectric materials with high energy density, ${ }^{7)-9)}$ the perovskite $\mathrm{Ba}_{0.3} \mathrm{Sr}_{0.7} \mathrm{TiO}_{3}$ ceramic was selected as our study material for its relatively high permittivity and high breakdown strength. ${ }^{10)}$

Compact pulsed power system requires large size dielectrics to enhance the output power. So a long-term aim of this research is to enable the fabrication of large sizes of high energy ceramics. However, the evolution of stress correlated with shrinkage mismatch during sintering can result in void formation, distortion and cracks in the large sizes densification bodies, ${ }^{11)}$ which make the fabrication of large size ceramics with high bulk density very difficult. This problem can be solved partially through the improvement of microstructure and composition of the ceramics. Recently, a novel sintering aid consisting of Borosilicate glasses was added in dielectric ceramics for its high electrical resistivity and good ability to wet dielectric ceramics. ${ }^{6), 12-16)}$ The main focus of those works had been on reducing the sintering temperature and refining the resulting microstructure. However, the details about the effects of glass concentration on densification behavior and dielectric properties were seldom reported. In this paper, the effects of $\mathrm{BaO}-\mathrm{Al}_{2} \mathrm{O}_{3}-\mathrm{B}_{2} \mathrm{O}_{3}-\mathrm{SiO}_{2}$ glasses concentration on the densification behavior, microstructure, and resulting dielectric properties of $\mathrm{Ba}_{0.3} \mathrm{Sr}_{0.7} \mathrm{TiO}_{3}$ ceramics were investigated.

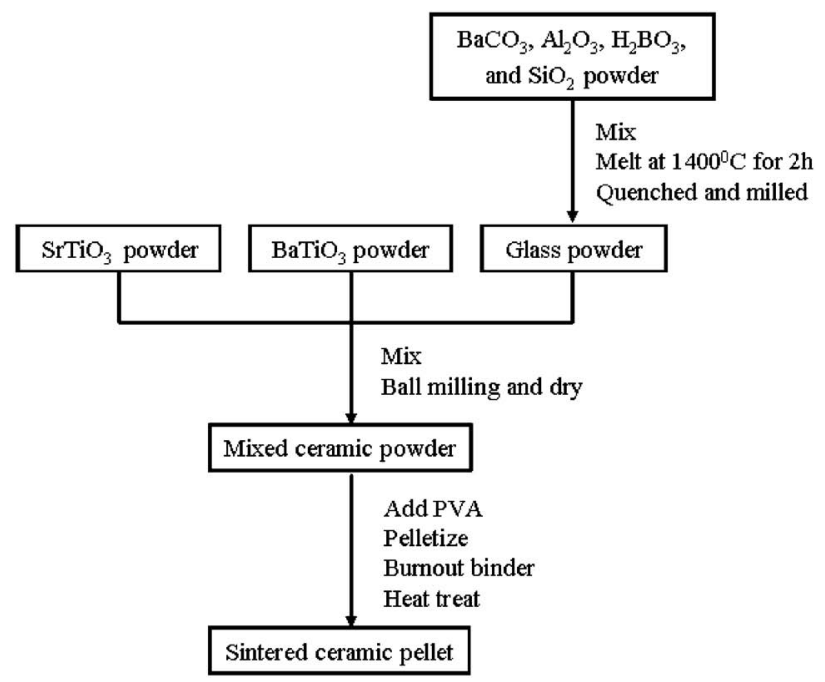

Fig. 1. Flow chart for the Fabrication of the glass added ceramics.

Table 1. Properties of the $\mathrm{BaO}-\mathrm{Al}_{2} \mathrm{O}_{3}-\mathrm{B}_{2} \mathrm{O}_{3}-\mathrm{SiO}_{2}$ Glass

\begin{tabular}{ccc}
\hline $\mathrm{T}_{\mathrm{m}} \backslash{ }^{\circ} \mathrm{C}$ & Density $\backslash \mathrm{g} \mathrm{cm}^{-3}$ & Dielectric constant \\
\hline$\sim 1050$ & 2.58 & $\sim 5.3$ \\
\hline
\end{tabular}

\section{Experimental procedure}

The experimental procedure adopted for the fabrication of the ceramics is depicted in Fig. 1. The purity of starting materials is higher than $99 \%$. The glass of composition, 35 mass $\% \mathrm{BaO}-15$ mass $\% \mathrm{Al}_{2} \mathrm{O}_{3}-15$ mass $\% \quad \mathrm{~B}_{2} \mathrm{O}_{3}-35$ mass $\%$ $\mathrm{SiO}_{2}$, was prepared. Table 1 summarize the properties of the Borosilicate glass prepared in this work. The glass powder was mixed with $\mathrm{SrTiO}_{3}$ and $\mathrm{BaTiO}_{3}$ powders in the ratio cor- 
responding to the following chemical composition: $\mathrm{Ba}_{0.3} \mathrm{Sr}_{0.7}$ $\mathrm{TiO}_{3}-x$ mass $\%$ glass, where $x=0$ mass $\%$ (BST), $x=1$ mass\% (BSTG1), 2 mass\% (BSTG2), 4 mass\% (BSTG4), 6 mass\% (BSTG6) and 8 mass\% (BSTG8) respectively.

To investigate densification behavior, the shrinkage of the green compacts with sintering was measured using a dilatometer (Model DL9700, ULVAC, Yokohama, Japan). The specimen was $6 \mathrm{~mm} \phi \times 15 \mathrm{~mm}$. The shrinkage measurements were performed in the range from room temperature to $1500^{\circ} \mathrm{C}$ at heating rate of $5^{\circ} \mathrm{C} / \mathrm{min}$ in air. The measurements of glass melting point and wetting angle were carried out by placing a $3 \mathrm{~mm}-3 \mathrm{~mm}$ cube of glass on top of the dense $\mathrm{Ba}_{0.3} \mathrm{Sr}_{0.7} \mathrm{TiO}_{3}$ substrate. The glass sample was heated in a tube furnace at $5^{\circ} \mathrm{C} / \mathrm{min}$ to $1200^{\circ} \mathrm{C}$. During this process, a camera was used to capture the melting behavior and to determine the melting point and wetting angle. The crystalline phases of the prepared samples were investigated by powder X-ray diffraction (XRD) (Model D/MAX-RB, RIGAKU Corporation, Japan). The microstructures of the sintered specimen were observed using a scanning electron microscope (SEM) (Model JSM-5610LV, JEOL Ltd., Japan). The bulk densities of the sintered pellets were measured by Archimedes method. The dielectric properties of the specimens with $20 \mathrm{~mm}$ diameter and $1 \mathrm{~mm}$ thickness were measured by HP4294 impedance analyzer at the frequency $1 \mathrm{MHz}$. All the dielectric constant values reported here have been corrected for the porosity using relation: ${ }^{17)}$

$$
\varepsilon_{\mathrm{r}}=\varepsilon\left(\frac{2+V}{2(1-V)}\right)
$$

Where $V=$ Volume fraction of pores, $\varepsilon=$ measured dielectric constant and $\varepsilon_{\mathrm{r}}=$ dielectric constant corrected for porosity. The DC breakdown tests were performed at room temperature. All samples were immersed in silicon oil to prevent flashover and corona discharge.

\section{Results and discussion}

\subsection{Densification of the samples}

Figure 2 shows the effect of glass concentration on sintering temperature of the samples, at which the maximum relative density can be obtained for each composition. We can see the glass content of 1 mass \% decreases the sintering temperature by about $50^{\circ} \mathrm{C}$. Increasing the glass fraction from 1 to 8 mass \% can decrease the sintering temperature by $200^{\circ} \mathrm{C}$. For the relative density, the maximum value increases from $95.3 \%$ to $98.7 \%$ as the glass content increases from 0 to 4 mass $\%$. A further increase in the glass content results in a decrease in relative density.

Then the study was designed to investigate the effect of glass additive on the densification behavior of green compacts of these compositions. Figure 3 shows a comparison of the shrinkage behaviors between pure BST and glass added BST compositions. The relative density of each green compact is about $55 \%$. For pure BST composition, densification starts at temperature about $1250^{\circ} \mathrm{C}$ and approaches its end at about $1350^{\circ} \mathrm{C}$. For glass added BST compositions, both the onset and the end temperature of densification drop gradually as the amount of glass additive increases. The shrinkage curve shows the shrinkage of BST specimens has been completed in a narrow range of $100^{\circ} \mathrm{C}$. However, as glass additives added in BST, the same process has been completed over a wide range of $250-350^{\circ} \mathrm{C}$. It is evident that addition of glass additives can decrease the densification temperature

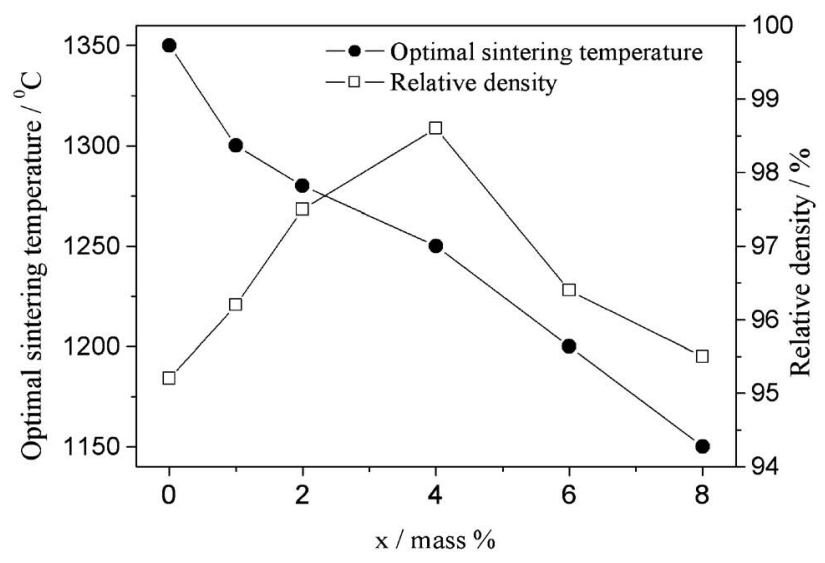

Fig. 2. Effect of glass content on optimal sintering temperature and relative density for BST samples.

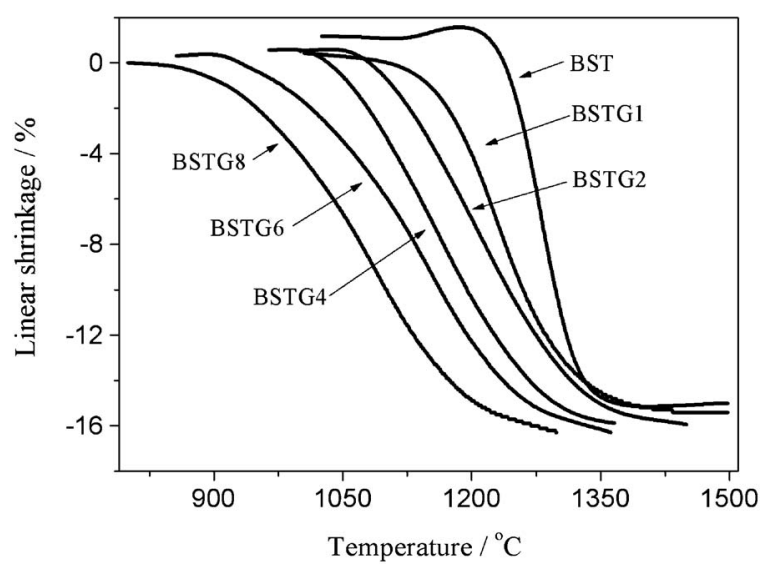

Fig. 3. Effects of glass content on the linear shrinkage as a function of temperature for BST samples fired at $5^{\circ} \mathrm{C} / \mathrm{min}$.

and widen the temperature range of densification remarkably. This can be attributed to the liquid formation between the grains during sintering.

Figure 4 shows the shrinkage rate as a function of temperature for BST, BSTG1, BSTG2, BSTG4, BSTG6 and BSTG8 specimens. The shrinkage rate reveals a sharp peak for BST composition whereas glass added compositions reveal rounded peaks, which indicates that densification mechanisms of these compositions may be different. The shrinkage rate of BST reaches relative high values of about $1.1 \% / \mathrm{min}$ at the temperature of the peak maximum. For the glass added compositions, however, the maximum values of shrinkage rate decrease remarkably to less $0.4 \% / \mathrm{min}$. As the glass concentration increases, the curves of the shrinkage rate of glass added compositions are very similar in shape but shift to lower temperature.

It was reported that the evolution of stress during sintering can result in void formation, cracks and the loss of dimensional tolerance. One common source of stresses in densifying bodies is the density gradients that develop during the formation of green bodies. ${ }^{11)}$ So the effect of the green density on the densification behavior of pure BST and glass added BST should be investigated. Figure 5 shows the sintering shrinkage rate as a function of temperature for the 45,50 , 


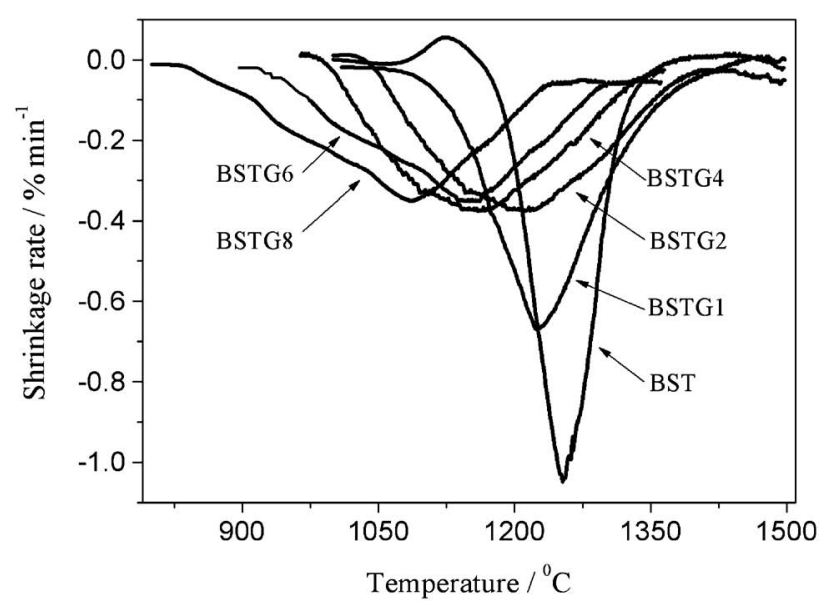

Fig. 4. Effects of glass content on the shrinkage rate as a function of temperature for BST samples fired at $5^{\circ} \mathrm{C} / \mathrm{min}$.

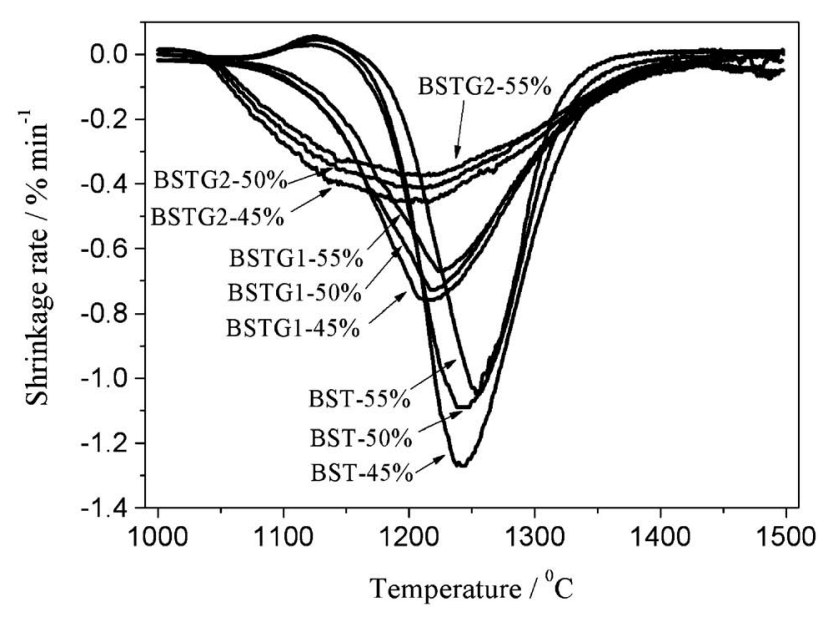

Fig. 5. Shrinkage rate versus temperature of pure and glass added BST for specimens with three different green densities. Samples were sintered at $5^{\circ} \mathrm{C} / \mathrm{min}$ to $1500^{\circ} \mathrm{C}$.

and 55\% green density samples. For the pure BST, the maximum shrinkage rates increase with decreasing green density and shift to lower temperature. The shrinkage rate mismatch at a given temperature can be as high as $0.4 \% / \mathrm{min}$ between the green density extremes of 45 and $55 \%$. Similar varies of the maximum shrinkage rate also be observed in the sintering cycle of the glass added compositions. However, the shrinkage rate mismatch at a given temperature is much lower than that of pure BST, which is about $0.2 \% / \mathrm{min}$ for BSTG1 and $0.1 \% / \mathrm{min}$ for BSTG2 respectively. Since the curves of the shrinkage rate of BSTG4, BSTG6 and BSTG8 are very similar in shape, we can predict that the shrinkage rate mismatch of these compositions may be as low as $0.1 \% / \mathrm{min}$.

Our recent work on the fabrication of large sizes ceramic shows voids and cracks often developed in large size pure $\mathrm{Ba}_{0.3} \mathrm{Sr}_{0.7} \mathrm{TiO}_{3}$ ceramics. Figure 6 shows representative voids and cracks occurred in the large sizes pure BST sample after heating to $1350^{\circ} \mathrm{C}$. This can be due to the evolution of stress that resulted from large mismatch in shrinkage rates during sintering. Since green density gradient usually occurs in a
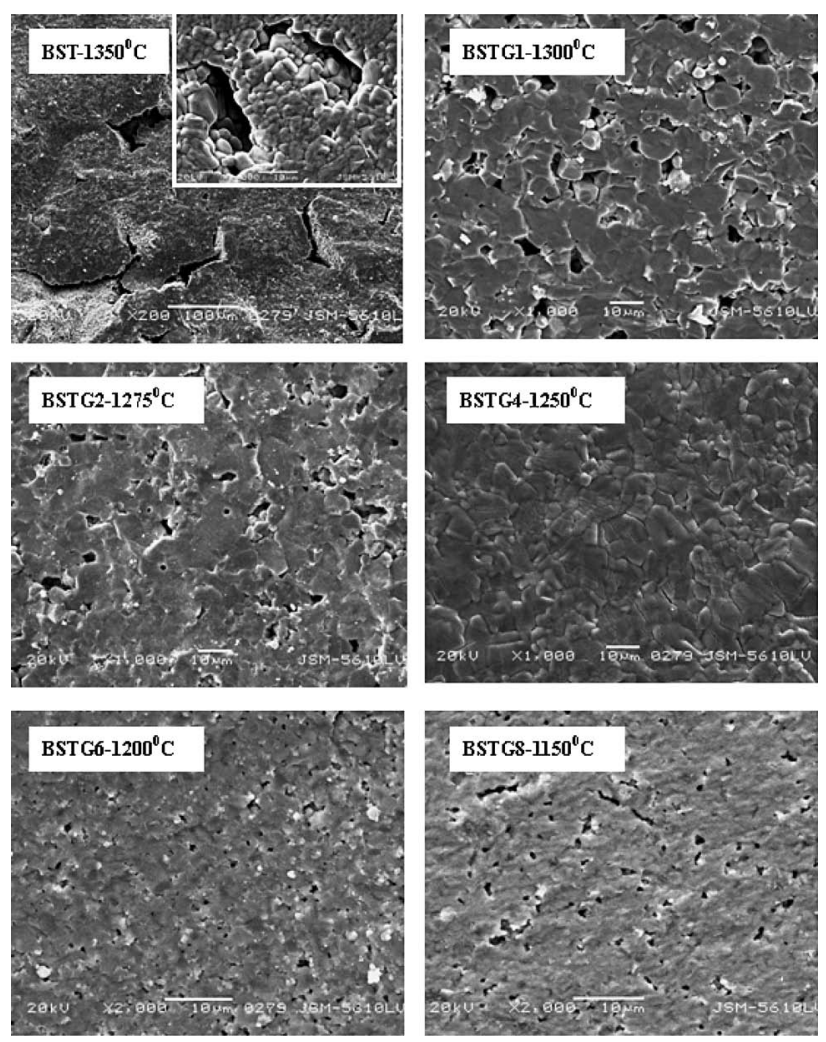

Fig. 6. Microstructure of pure BST and glass added BST. All samples prepared with a hold time of $2 \mathrm{~h}$ at the optimal sintering temperature.

large size green compact, the results shown in Fig. 5 indicate that a large shrinkage rate mismatch would occur in the pure BST bodies during the densification. This large mismatch in shrinkage rate is responsible for stresses that arise during the densification, which consequently causes void formation and cracks in sintering compact. ${ }^{11), 18}$

For the glass added samples, the results shown in Fig. 5 indicate that the shrinkage mismatch caused by green density gradient can be reduced remarkably. It can be predicted that the development of stress correlated with shrinkage mismatch can be restrained and ultimately the void formation, distortion and cracks in large size ceramics can be prevented. This contribution can be supported by the modification of the microstructure of the glass added samples. Representative fractured surface images shown in Fig. 6 reveal that few void or crack occurred in the glass added sintered bodies. The BSTG1 exhibits large grain growth with an average grain size of $10 \mu \mathrm{m}$ after a 2 -h hold. But Some large size pores with a diameter of $5-10 \mu \mathrm{m}$ were observed at the grain boundary. Additions of only 2-4 mass $\%$ glass caused little change in the grain size after a 2 -h hold. But both the number and size of pore decreased remarkably. Especially for BSTG4, the sample exhibits a very dense microstructure with virtually almost no porosity and a continuous grain boundary. A further increase of glass content reduced the grain size of the samples remarkably, which may be due to the decreasing sintering temperate. BSTG6 had an average grain size of about $2 \mu \mathrm{m}$, and BSTG8 had an average grain size of about $1 \mu \mathrm{m}$. However, the microstructure of these samples became more porous. Many pores which are small in 


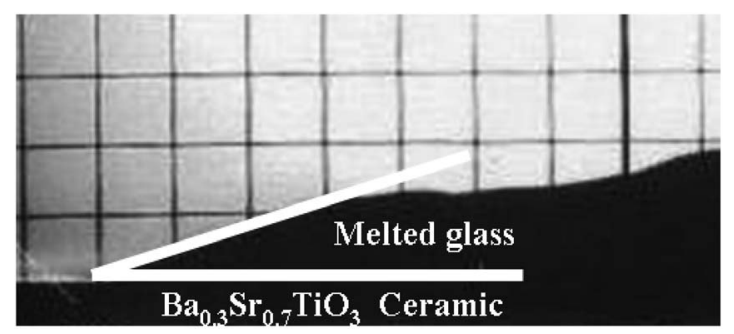

Fig. 7. Wetting behavior of glass on the $\mathrm{Sr}_{0.7} \mathrm{Ba}_{0.3} \mathrm{TiO}_{3}$ substrate at $1150^{\circ} \mathrm{C}$.

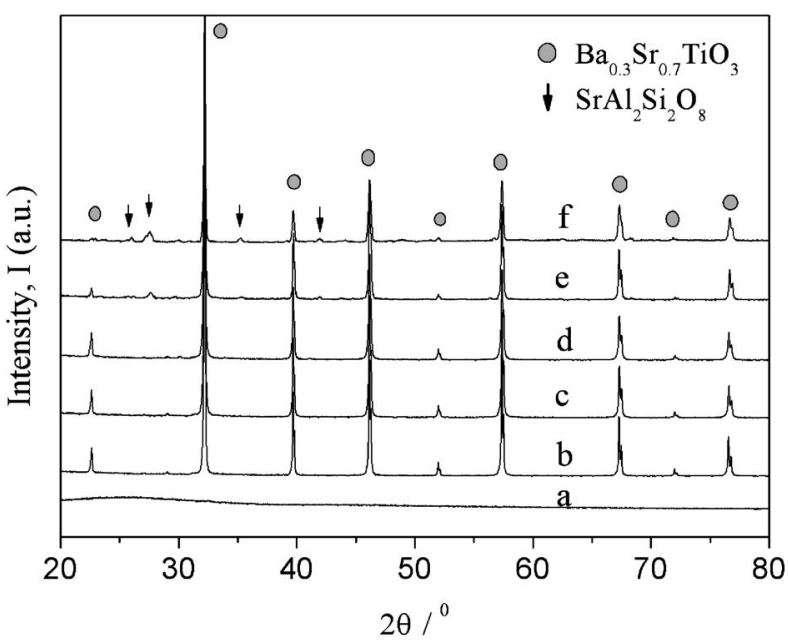

Fig. 8. XRD patters of pure BST and glass added BST samples: (a) quenched glass powders, (b) pure BST, $1350^{\circ} \mathrm{C}$ for $2 \mathrm{~h}$, (c) BSTG2, $1275^{\circ} \mathrm{C}$ for $2 \mathrm{~h}$, (d) BSTG4, $1250^{\circ} \mathrm{C}$ for $2 \mathrm{~h}$, (e) BSTG6, $1200^{\circ} \mathrm{C}$ for $2 \mathrm{~h}$, (f) BSTG8, $1150^{\circ} \mathrm{C}$ for $2 \mathrm{~h}$.

size occur at grain boundary.

The above experimental results show that the presence of 4 mass\% glass phase is enough to cause mobility of the $\mathrm{Ba}_{0.3} \mathrm{Sr}_{0.7} \mathrm{TiO}_{3}$ particles and to result in a nearly model microstructure with high density. This indicates a well ability of this glass to wet the $\mathrm{Ba}_{0.3} \mathrm{Sr}_{0.7} \mathrm{TiO}_{3}$ ceramic. It can be supported by the low wetting angle of the melted glass on $\mathrm{Ba}_{0.3} \mathrm{Sr}_{0.7} \mathrm{TiO}_{3}$ ceramic shown in Fig. 7, which is only about $18^{\circ}$. The porous microstructure, resulted from excess addition of glass phase, may be related to the formation of second phase in glass compositions under typical sintering conditions. The XRD profiles in Fig. 8 show some extra weak peaks related to $\mathrm{SrAl}_{2} \mathrm{Si}_{2} \mathrm{O}_{8}$ phase emerge in the samples with glass content higher than 4 mass $\%$. It indicates that an interfacial reaction takes place between $\mathrm{Ba}_{0.3} \mathrm{Sr}_{0.7} \mathrm{TiO}_{3}$ and glasses. The second phase may degrade the densification as well as retard the grain growth, and resulted in the porous microstructure. ${ }^{14), 16)}$ This is consistent with the decrease in final density of BSTG6 and BSTG8 shown in Fig. 2.

\subsection{Dielectric properties of the samples}

Figure 9 shows the average breakdown strength for samples prepared under their optimum sintering conditions. A total of 20 samples for each composition were tested. The pure BST has average breakdown strength of $11.2 \mathrm{kV} / \mathrm{mm}$. Glass addition as high as 4 mass\% increased remarkably the

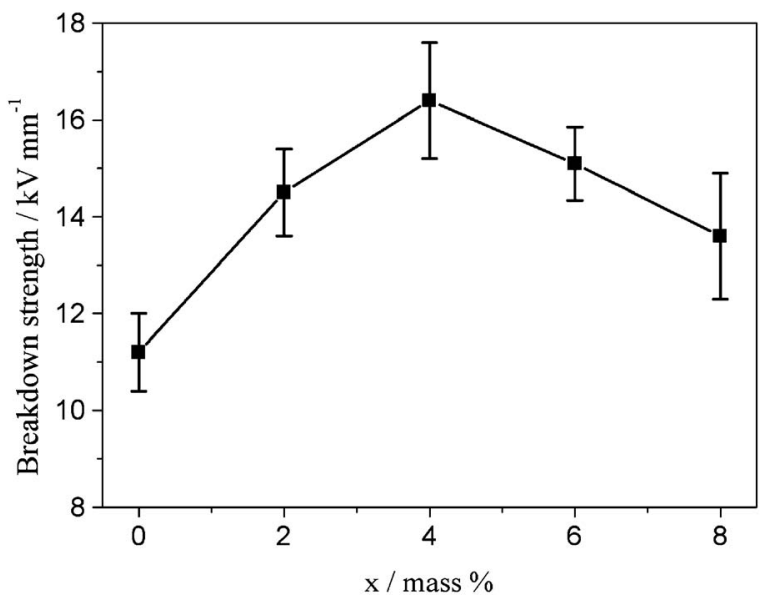

Fig. 9. Effects of glass content on average breakdown strength of glass added BST samples.

breakdown strength to $16.4 \mathrm{kV} / \mathrm{mm}$. A further increase of glass additive concentration, however, caused a slightly decrease of breakdown strength of the samples.

The breakdown strength of ceramics also depends strongly on extrinsic effects such as porosity and grain size. Breakdown strength can be improved through increasing density, eliminating large size pore and reducing the grain size. ${ }^{3), 5)}$ In this work, the improvement in breakdown strength of glass added BST can be attributed to the corresponding decrease in porosity. The glass additions improved the density from 95.2\% for the pure BST to $98.6 \%$ for the BSTG4. This is the reason why BSTG4 shows higher breakdown strength. However, the results in our study also show that an excessive addition of glass has caused an undesirable damage of the breakdown strength, although the average grain size reduced to $1-2 \mu \mathrm{m}$. This could be due to the occurrence of many pores in the samples, which reduced the relative density and consequently damaged the breakdown strength. For the samples with glass content higher than 4 mass $\%$, it seems that it is not grain size but the pores, which is the dominating cause of the damage of the breakdown strength.

The variation of dielectric properties at room temperature is plotted in Fig. 10. The results show that the room temperature dielectric constant decreases gradually from 685 for the pure BST to 296 as glass content increases to 8 mass \%. This decrease seems to be natural as the dielectric constant of the glass $\left(\varepsilon_{\mathrm{r}}=5.3\right)$ is much lower than that of the pure BST ceramics $\left(\varepsilon_{\mathrm{r}}=685\right)$. The observed values of dielectric constant for glass added samples are in agreement with the values computed by the logarithmic mixing rule for a binary mixture, as shown in Fig. 10. The little difference of the values between computed and observed dielectric constant for BSTG8 may be due to the formation of $\mathrm{SrAl}_{2} \mathrm{Si}_{2} \mathrm{O}_{8}$ phase, which has a higher dielectric constant $\left(\varepsilon_{\mathrm{r}}=6-8\right)$ than the glass. ${ }^{19)}$ The addition of glass phase usually increases the dielectric loss of the ceramic samples, especially at a high frequency. ${ }^{20)}$ The results in this work show that the addition of 2 mass $\%$ glass increases the dielectric loss from $4.6 \times 10^{-4}$ for pure BST to $3.2 \times 10^{-3}$. A further increase of the glass additions only causes a slightly variation of the values around $3 \sim 5 \times 10^{-3}$. 


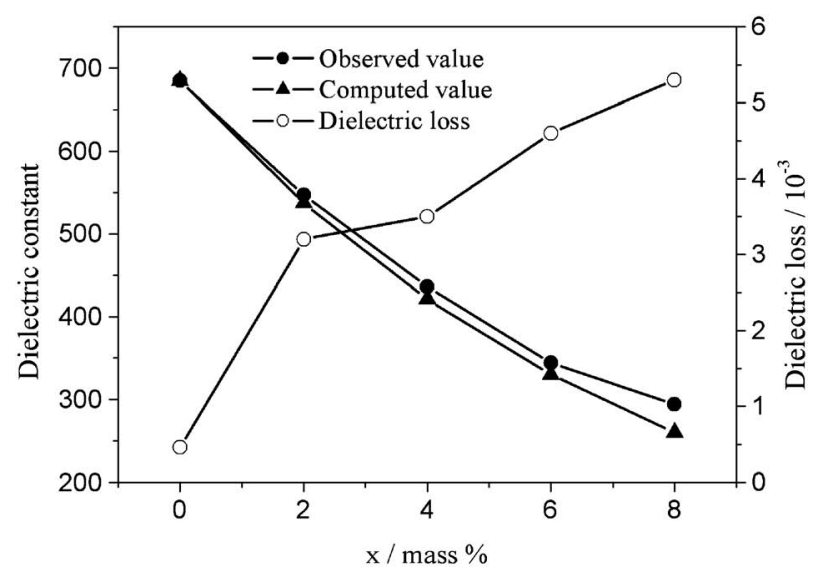

Fig. 10. Effects of glass content on the room temperature dielectric properties of BST samples.

\section{Conclusion}

The large size ceramics with compositions of $\mathrm{Ba}_{0.3} \mathrm{Sr}_{0.7}$ $\mathrm{TiO}_{3}$ and $0-8$ mass $\% \mathrm{BaO}-\mathrm{Al}_{2} \mathrm{O}_{3}-\mathrm{B}_{2} \mathrm{O}_{3}-\mathrm{SiO}_{2}$ glass additive were fabricated. The sintering temperature of the samples decreased form $1350^{\circ} \mathrm{C}$ to $1150^{\circ} \mathrm{C}$ as the glass content increased from 0 to 8 mass $\%$. The shrinkage rate and the shrinkage rate mismatch caused by green density gradient also reduced remarkably for the addition of the glass additives, which contribute to enable the fabrication of large sizes of ceramic with dense microstructure. For the samples containing $4 \mathrm{wt} \%$ glass additions, optimal dielectric properties were obtained: dielectric constant is 440 , dielectric loss is $3.5 \times 10^{-3}$ at $1 \mathrm{MHz}$, and breakdown strength is $16.4 \mathrm{kV} /$ $\mathrm{mm}$. The improvement of breakdown strength can be attributed to the modification of the microstructure.

Acknowledgement The authors would like to thank the support of Natural Science Foundation of China (Grand Num: 50472016), Ministry of Education of China (main project), Foundation for Innovative Research Team of Hubei province (Grand Num: 2005ABC004).

\section{References}

1) J. A. Gaudet, C. J. Buchenauer, C. Christodoulou, E. Schamiloglu and J. S. Tyo, Proceedings of the IEEE., 92, 1144-1164 (2004)

2) Y. Ye, S. C. Zhang and F. Dogan, et al., PPC-2003: $14^{\text {th }}$ IEEE International Pulsed Power Conference, Dallas (2003) pp. 719-722

3) B. Gilmore, Ph. D. thesis, University of Missouri-Rolla (2001).

4) R. V. Shende, D. S. Krueger, G. A. Rossetti and S. J. Lombardo, J. Am. Ceram. Soc., 84, 1648-1650 (2001).

5) Z. H. Wu, M. H. Cao, H. T. Yu, Z. H. Yao, D. B. Luo and H. X. Liu, The 4th Asian Meeting on Electroceramics, Hangzhou, China, June 27-30, (2005).

6) A. Young, W. G. Hilmas, S. C. Zhang and R. W. Schwartz, J. Am. Ceram. Soc., 90, 000-000 (2007).

7) J. W. McPherson, J. Kim, A. Shanware, H. Mogul and J. Rodriguez, IEEE Transactions on Electron Devices., 50, 1771-1778 (2003)

8) G. R. Love, J. Am. Ceram. Soc., 73, 323-328 (1990).

9) N. H. Fletcheryz, A. D. Hiltonxk and B. W. Rickettsy, J. Phys. D: Appl. Phys., 29, 253-258 (1996).

10) J. H. Jeon, J. Eur. Ceram. Soc., 24, 1045-1048 (2004).

11) S. E. Schoenberg, D. J. Green, A. E. Segall, G. L. Messing, A. S. Grader and P. M. Halleck, J. Am. Ceram. Soc., 89, 3027-3033 (2006).

12) W. Huebner, S. C. Zhang, B. Gilmore, M. L. Krogh, B. C. Schultz, R. C. Pate, L. F. Rinehart and J. M. Lundstron, In Proceedings of the 12th IEEE International Pulsed Power Conference (1999) pp. 1242-1245.

13) X. X. Wang, K. Murakami, O. Sugiyama and S. Kaneko, J. Eur. Ceram. Soc., 21, 1367-1370 (2001).

14) S. F. Wang, C. K. Yang, Y. R. Wang and Y. Kuromitsu, Ceramics International, 27, 157-162 (2001).

15) M. Z. Jhou and J. H. Jean, J. Am. Ceram. Soc., 89, 786-791 (2006).

16) H. P. Jeon, S. K. Lee, S. W. Kim and D. K. Choi, Materials Chemistry and Physics., 94, 185-189 (2005).

17) K. R. Chowdary and E. C. Subbarao, Ferroelectrics, 37, 689-692 (1981).

18) S. E. Schoenberg, D. J. Green and G. L. Messing, J. Am. Ceram. Soc., 89, 2448-2452 (2006).

19) Y. Kobayashi, M. Inagaki, J. Eur. Ceram. Soc., 24, 399-404 (2004).

20) H. K. Shin, H. Shin, S. Y. Cho and K. S. Hong, J. Am. Ceram. Soc., 88, 2461-2465 (2005). 